\title{
Effectiveness of an Instructional Program on Knowledge for Patients with Lumbar Disk Prolapse at Baghdad Teaching Hospitals
}

\author{
Shaymaa' M. Hussein, MSc.N ${ }^{1}$, Dr. Hussein H. Atiyah, $\mathrm{PhD}^{2}$ \\ ' (Teaching Assistant, Adult Nursing Department, College of Nursing, University of Baghdad, Iraq) \\ ${ }_{2}^{2}$ (Assistant Professor, Adult Nursing Department, College of Nursing, University of Baghdad, Iraq)
}

\begin{abstract}
Lumbar disk prolapse (LDP) is a major public health problem and highly percent of the adult population suffers from this disease at some time in their lives. Around 10\% of sufferers become chronically disabled patients and may also present with sciatic symptoms. The quality of life hence productivity is reduced due this disease. The Lumbar disk is weakened therefore; causing instability of the spine, which may result in changes and disk displacement, nerve root compression and canal stenosis. This disorder is common among middle-aged individuals, who are at large the working population so an enormous economic burden may be created in the society.
\end{abstract}

Objective: The study aims to determine the effect of the instructional program on knowledge of patients with LDP and to find out the relationship between patients' socio-demographic characteristics of gender, age, educational level, marital status, occupation, monthly income, type of residence and residential area and their knowledge related to $L D P$.

Methodology: A descriptive study was conducted on non-probability (purposive sample) of (60) patients; (30) patients for the study group and (30) for the control group, who had a lumbar disk prolapse in Baghdad teaching hospitals from October $15^{\text {th }}$, 2015 to July $20^{\text {th }}$, 2016.The same questionnaire form wasused for the study and control groups in the pretest period as a tool of data collection, which these data are introduced through the application of an instructional program.Then after three weeks; the post-test was given to both groups, after the program has been finished with the study group, and with same questionnaires that used in the pretest. Descriptive and inferentialstatistical analyses were used to analyze the data.

Results: The results of the LDP study group patients showed there are differences between their knowledge about LDP in pretest and their knowledge in post-test periods. Also, it reveals that there was a statistically no significant association at $(P \leq 0.05)$ between the study group of LDP patients' knowledge related to (age, gender, marital status, occupation and residential area), but there was a significant association related to the educational level.

Conclusion: the results showed that the study group of LDP patients benefited from the implementation of the instructional program, and their knowledge was effectively enhanced and established.

Recommendations: The study recommended the importance of increasing awareness among patients about the lumbar disk prolapse distributed through handbooks, explanatory posters, and performing an educational health programs through modern technological means (audio-visual) to follow a healthy back and spine safety during daily life activities at home and at work. Finally, the researchers suggest performing furtherlongitudinal studies that include a larger sample which assists in a more precise investigation of the quality of life of LDP clients.

Keywords: Instructional program, Knowledge, LDP, Patient.

\section{Introduction}

Lumbar disc prolapse is one of a public disabling disease in modern society. According to the World Health organization (WHO), LDP has become one of the most important causes of disability as expressed in disability-adjusted life years both in developed and developing countries ${ }^{[1,2]}$. The incidence of LDP is ranging from sixty to over than ninety percent. The young adult prevalence of this disease is low; it has been reported to be less than one percent between the individuals aged from ( 20 to 22 years). It's peaking for people aged from 41-50 years, while for persons aged more than eighty years, it was recounted to be $1: 4$ persons $^{[3,4,5,6]}$. Ninetyfive percent of herniation in the region occurs in the vertebral interspaces lumbar4 - lumbar5 and lumbar5 sacral $1^{[7]}$. Many factors can affect this disease, which include both spinal and additional related spinal conditions ${ }^{[8]}$. Conservative management is used most common, and the reporting of therapy effectiveness from the back pain care providers, in addition, these remedies may reduce the costs of care after the first course of therapy ${ }^{[9]}$. So, when these measures fail to achieve goals for those peoples, the considerations of surgical treatment should be done ${ }^{[10]}$. 


\section{Methodology}

A descriptive study was carried out in Baghdad teaching hospitals(Baghdad, AL-Kadhumia, AlKarama, Al-Kindy, Neurological Surgery and Ghazi Al-Hariri for Specialist Surgeries), from October $15^{\text {th }} 2015$ to July $20^{\text {th }}$, 2016to determine the effect of the instructional program on knowledge of patients with LDP and to find out the relationship between patients' socio-demographic characteristics of gender, age, educational level, marital status, occupation, monthly income, type of residence and residential area and their knowledge related to LDP. A purposive "non-probability" sample of (60) patients (30 patients in the control group and 30 patients in the study group) who had had a lumbar disk prolapse were selected. A direct structured interview with the patient was used for data collection. Three weeks later, the post-Test was given to both groups, after the program has been finished with the study group. Questionnaire form consists of three parts; the first part is about the socio-demographic information; the second part encompasses the patient's clinical and surgical history; and third part involves the patients' knowledge about lumbar disk prolapse. The content validity of the questionnaire form was recognized through displaying it on (16) experts with competence and the reliability have been determined through the pilot study, which was conducted from February $21^{\text {th }}$ to March $6^{\text {th }}, 2016$ and the application of the Pearson correlation coefficient. The methods of descriptive and inferential statistics are used when the data have been analyzed.

III. Results

Table 1.Participants' Socio-demographic Characteristics $(\mathrm{N}=60)$

\begin{tabular}{|c|c|c|c|c|}
\hline \multirow{2}{*}{ Variables } & \multicolumn{2}{|c|}{ Study Group } & \multicolumn{2}{|c|}{ Control Group } \\
\hline & Frequency & Percent & Frequency & Percent \\
\hline Male & 13 & 43.3 & 15 & 50 \\
\hline Female & 17 & 56.7 & 15 & 50 \\
\hline Age(Years) & Frequency & Percent & Frequency & Percent \\
\hline $20-29$ & 5 & 16.7 & 5 & 16.7 \\
\hline $30-39$ & 9 & 30 & 10 & 33.3 \\
\hline $40-49$ & 7 & 23.3 & 8 & 26.7 \\
\hline 50 and above & 9 & 30 & 7 & 23.3 \\
\hline Level of Education & Frequency & Percent & Frequency & Percent \\
\hline Unable to read and write & 2 & 6.7 & 1 & 3.3 \\
\hline Read \& Write & 2 & 6.7 & 5 & 16.7 \\
\hline Primary school graduate & 10 & 33.3 & 8 & 26.7 \\
\hline Intermediate school graduate & 6 & 20 & 2 & 6.7 \\
\hline $\begin{array}{c}\text { Secondary school graduate } \\
4.5 . \text { Secondary }\end{array}$ & 5 & 16.7 & 5 & 16.7 \\
\hline Diploma & 1 & 3.3 & 1 & 3.3 \\
\hline Bachelor & 4 & 13.3 & 6 & 20 \\
\hline Graduate Degree & 0 & 0 & 2 & 6.7 \\
\hline Marital Status & Frequency & Percent & Frequency & Percent \\
\hline Married & 25 & 83.3 & 26 & 86.7 \\
\hline Single & 5 & 16.7 & 4 & 13.3 \\
\hline Governmental employee & 6 & 20 & 10 & 33.3 \\
\hline Free job & 9 & 30 & 7 & 23.3 \\
\hline Retired & 1 & 3.3 & 1 & 3.3 \\
\hline Student & 1 & 3.3 & 1 & 3.3 \\
\hline Housewife & 13 & 43.3 & 10 & 33.3 \\
\hline Unemployed & 0 & 0 & 1 & 3.3 \\
\hline Monthly Income & Frequency & Percent & Frequency & Percent \\
\hline Sufficient & 11 & 36.7 & 12 & 40 \\
\hline Barely sufficient & 14 & 46.7 & 11 & 36.7 \\
\hline Insufficient & 5 & 16.7 & 7 & 23.3 \\
\hline Type of Residence & Frequency & Percent & Frequency & Percent \\
\hline Private property & 20 & 66.7 & 19 & 63.3 \\
\hline Rented & 10 & 33.3 & 11 & 36.7 \\
\hline Residential Area & Frequency & Percent & Frequency & Percent \\
\hline Urban & 27 & 90 & 26 & 86.7 \\
\hline Rural & 3 & 10 & 4 & 13.3 \\
\hline
\end{tabular}


Table (1) shows that the majority of $(56.7 \%)$ were female in the study group and $(50 \%)$ for each male and female in control group. Most of the study group (30\%) from the age group (30-35) years and (50 years and older), and (33.3\%) were the age group (30-35) years for the control group.

The majority of $(33.3 \%)$ were primary school graduation, these for the study group while $(26.7 \%)$ for the control group was graduated from primary school. Most of $(83.3 \%)$ of the study group were married, and $(86.7 \%)$ were married also from the control group.

The housewife occupation formed a (43.3\%) of the study group while for the control group, a (33.3\%) which was the highest rate for each a governmental employee and a housewife. The majority of $(46.7 \%)$ of the study group, the monthly income was barely sufficient, and (40\%) were sufficient monthly income for the control group.

Most of $(66.7 \%)$ were private property residence for the study group, and $(63.3 \%)$ from the control group were also private property residence. The vast majority of the study group people live in urban $\operatorname{areas}(90 \%)$, and $(86.7 \%)$ of the control group live in urban areas too.

Table 2.Participants' Clinical Characteristics $(\mathrm{N}=60)$

\begin{tabular}{|c|c|c|c|c|}
\hline \multirow{2}{*}{$\begin{array}{c}\text { Variables } \\
\text { Suffering from Chronic Disease }\end{array}$} & \multicolumn{2}{|c|}{ Study Group } & \multicolumn{2}{|c|}{ Control Group } \\
\hline & Frequency & Percent & Frequency & Percent \\
\hline Yes & 7 & 23.3 & 5 & 16.7 \\
\hline No & 23 & 76.7 & 25 & 83.3 \\
\hline Type of Chronic Disease & Frequency & Percent & Frequency & Percent \\
\hline Having no disease & 23 & 76.7 & 24 & 80 \\
\hline Diabetes Mellitus & 1 & 3.3 & 1 & 3.3 \\
\hline Hypertension & 3 & 10 & 4 & 13.3 \\
\hline Asthma & 2 & 6.7 & 1 & 3.3 \\
\hline Kidney Atrophy & 1 & 3.3 & 0 & 0.0 \\
\hline Smoking & Frequency & Percent & Frequency & Percent \\
\hline Yes & 2 & 6.7 & 2 & 6.7 \\
\hline No & 28 & 93.3 & 28 & 93.3 \\
\hline Years of Smoking & Frequency & Percent & Frequency & Percent \\
\hline No year & 25 & 83.3 & 28 & 93.3 \\
\hline (1-5) year & 1 & 3.3 & 0 & 0 \\
\hline$(6-10)$ year & 3 & 10 & 0 & 0 \\
\hline$(11-15)$ year & 0 & 0 & 1 & 3.3 \\
\hline 16 and above & 1 & 3.3 & 1 & 3.3 \\
\hline Existence of Family Members Having LDP & Frequency & Percent & Frequency & Percent \\
\hline Yes & 9 & 30 & 5 & 16.7 \\
\hline No & 21 & 70 & 25 & 83.3 \\
\hline Having Previous Disk Surgery & Frequency & Percent & Frequency & Percent \\
\hline Yes & 2 & 6.7 & 0 & 0 \\
\hline No & 28 & 93.3 & 30 & 100 \\
\hline $\begin{array}{l}\text { Previous Admission to the Hospital Due to the } \\
\text { Symptoms }\end{array}$ & Frequency & Percent & Frequency & Percent \\
\hline Yes & 12 & 40 & 10 & 33.3 \\
\hline No & 18 & 60 & 20 & 66.7 \\
\hline $\begin{array}{c}\text { Having symptoms of LDP Lead to Work } \\
\text { Absenteeism }\end{array}$ & Frequency & Percent & Frequency & Percent \\
\hline Not belonged to governmental work & 15 & 50 & 13 & 43.3 \\
\hline Yes & 8 & 26.7 & 16 & 53.3 \\
\hline No & 7 & 23.3 & 1 & 3.3 \\
\hline
\end{tabular}

Table (2) shows that the majority of $(76.7 \%)$ weren't suffering from chronic disease for the study group, and most of $(83.3 \%)$ of the control group weren't suffering from it also. Most of subjects in the study group haven't any type of chronic disease $(76.7 \%)$, and higher proportion in the control group also haven't any type of chronic disease $(83.3 \%)$.

The vast majority of the study group are non-smokers $(93.3 \%)$, and the majority of subjects in the control group are non-smokers $(83.0 \%)$.

Patients who have no family members with lumbar disk prolapse were (70\%) for the study group and $(83.3 \%)$ for the control group. The vast majority of subjects in the study group have no pervious disk surgery $(93.3 \%)$, and all subjects in the control group have no previous disk surgery (100.0\%). Most of subjects haveno previous admission to the hospital due to the symptoms $(60 \%, 66.7 \%)$ for the study and the control groupsrespectively. A half of subjects in the study group didn't have work absenteeism (50\%) and this proportion was higher for the control group (43.3\%) because they weren't governmental employees. 
Effectiveness of an Instructional Program on Knowledge for Patients with Lumbar Disk Prolapse ....

Table 3.Participants' Knowledge and Mean of Scores in the Pre-Test Period (N=60)

\begin{tabular}{|c|c|c|c|c|c|c|c|c|}
\hline \multirow{2}{*}{$\begin{array}{l}\text { Level of Patients } \\
\text { Knowledge }\end{array}$} & \multicolumn{4}{|c|}{ Study Group } & \multicolumn{4}{|c|}{ Control Group } \\
\hline & Frequency & Percent & Mean of Scores & Severity & Frequency & Percent & Mean of Scores & Severity \\
\hline Low & 20 & 66.7 & \multirow{4}{*}{1.33} & \multirow{4}{*}{$\mathrm{L}$} & 21 & 70 & \multirow{4}{*}{1.30} & \multirow{4}{*}{$\mathrm{L}$} \\
\hline Moderate & 10 & 33.3 & & & 9 & 30 & & \\
\hline High & 0 & 0 & & & 0 & 0 & & \\
\hline Total & 30 & 100 & & & 30 & 100 & & \\
\hline
\end{tabular}

Severity: low (1-1.4), moderate (1.5- 2.4), high (2.5-3).

Table (3) shows that most of the subjects in the study group have low knowledge level (66.6\%), and this proportion is higher for the control group $(70 \%)$.

Table 4.Participants'Knowledge and Mean of Scoresin the Post-Test Period (N=60)

\begin{tabular}{|c|c|c|c|c|c|c|c|c|}
\hline \multirow{2}{*}{$\begin{array}{l}\text { Level of Patients } \\
\text { Knowledge }\end{array}$} & \multicolumn{4}{|c|}{ Study Group } & \multicolumn{4}{|c|}{ Control Group } \\
\hline & Frequency & Percent & Mean of Scores & Severity & Frequency & Percent & Mean of Scores & Severity \\
\hline Low & 0 & 0 & \multirow{4}{*}{2.60} & \multirow{4}{*}{$\mathrm{H}$} & 21 & 70 & \multirow{4}{*}{1.37} & \multirow{4}{*}{$\mathrm{L}$} \\
\hline Moderate & 10 & 33.3 & & & 7 & 23.3 & & \\
\hline High & 20 & 66.7 & & & 2 & 6.7 & & \\
\hline Total & 100 & 30 & & & 30 & 100 & & \\
\hline
\end{tabular}

Table (4) shows that most of the subjects in the study group havea highlevel of knowledge $(66.7 \%)$ in the post-test period. However, most of the subjects in the control group have a low level of knowledge (70\%).

Table 5.Distribution ofthe Rate of Scores According to the Study Group Post-Test Knowledge Response about LDP

\begin{tabular}{|c|c|c|}
\hline Variables & Frequency & Percent \\
\hline \multicolumn{3}{|l|}{ Rate of Anatomy Score } \\
\hline Moderate & 11 & 36.7 \\
\hline High & 19 & 63.3 \\
\hline Total & 30 & 100 \\
\hline Rate of Etiology Score & Frequency & Percent \\
\hline Moderate & 12 & 40 \\
\hline High & 18 & 60 \\
\hline Total & 30 & 100 \\
\hline Rate of Symptoms and Complications Score & Frequency & Percent \\
\hline Moderate & 12 & 40 \\
\hline High & 18 & 60 \\
\hline Total & 30 & 100 \\
\hline Rate of Prevention Methods Score & Frequency & Percent \\
\hline Moderate & 2 & 6.7 \\
\hline High & 28 & 93.3 \\
\hline Total & 30 & 100 \\
\hline Rate of Total Items Score for Patient' Knowledge & Frequency & Percent \\
\hline Moderate & 10 & 33.3 \\
\hline High & 20 & 66.7 \\
\hline Total & 30 & 100 \\
\hline
\end{tabular}

Table (5) shows that the high rate of score was for anatomy part $(63.3 \%),(60 \%)$ for etiology part, the higher rate of score for signs, symptoms, and complications part was (60\%), a high rate was for prevention methods part $(93.3 \%)$, and $(66.7 \%)$ for total items rate of patients' knowledgeinstudy group in the post-Test period.

Table 6.Association between theStudy Group's Age and Their KnowledgeTotal Items Rate in the Post-Test

\begin{tabular}{|c|c|c|c|}
\hline \multirow{2}{*}{ Age (Years) } & \multicolumn{2}{|c|}{\begin{tabular}{c}
\multirow{2}{*}{ Total Items Rate of Patients' Knowledge for the Study } \\
Group Posttest
\end{tabular}} & \multirow{2}{*}{$\begin{array}{c}\text { High } \\
\text { f }\end{array}$} \\
\cline { 2 - 4 } & $\begin{array}{c}\text { Moderate } \\
\text { f }\end{array}$ & 5 & 5 \\
\hline $\mathbf{2 0 - 2 9}$ & 0 & 4 & 9 \\
\hline $\mathbf{3 0 - 3 9}$ & 5 & 5 & 9 \\
\hline $\mathbf{4 0 - 4 9}$ & 2 & 6 & 30 \\
\hline $\mathbf{5 0}$ and older & 3 & \multicolumn{2}{c}{$\chi^{2}$ obs. 4.571} \\
\hline Total & 10 & $\mathrm{P} \leq 0.05$ & \\
\hline $\mathrm{df}=3$ & $\chi^{2}$ crit. $=7.815$ & \multicolumn{2}{c}{} \\
\hline
\end{tabular}


$\mathrm{df}=$ degree of freedom, $\chi^{2}$ Crit. $=$ Chi-Square critical, $\mathrm{P}=$ probability, $\chi^{2}$ Obs. $=$ Chi-Square Observed

Table (6) shows that there is no significant difference between total items rate of patients' knowledge related to lumbar disk prolapse with their age.

Table 7.Association between theStudy Group's Gender and Their KnowledgeTotal Items Rate in the Posttest

\begin{tabular}{|c|c|c|c|}
\hline \multirow{3}{*}{ Gender } & \multicolumn{2}{|c|}{ Total Items Rate of Patients' Knowledge for the Study Group Posttest } & \multirow{2}{*}{ Total } \\
\cline { 2 - 4 } & $\begin{array}{c}\text { Moderate } \\
\text { f }\end{array}$ & $\begin{array}{c}\text { High } \\
\text { f }\end{array}$ & 10 \\
\hline Male & 3 & 10 & 13 \\
\hline Female & 7 & 20 & 30 \\
\hline Total & 10 & $\mathrm{P} \leq 0.05$ & $\chi^{2}$ obs. $=1.086$ \\
\hline \multicolumn{2}{|r}{} \\
\hline
\end{tabular}

Table (7) shows that there is no significant difference between total items rate of patients' knowledge related to lumbar disk prolapse with gender.

Table 8.Association between the Study Group's Marital Status and Their Knowledge Total Items Rate in the Posttest

\begin{tabular}{|c|c|c|c|}
\hline \multirow{3}{*}{ Marital Status } & \multicolumn{2}{|c|}{ Total Items Rate of Patients' Knowledge for the Study } \\
Group Posttest & \multirow{2}{*}{ Total } \\
\cline { 2 - 4 } & $\begin{array}{c}\text { Moderate } \\
\text { f }\end{array}$ & $\begin{array}{c}\text { High } \\
\text { f }\end{array}$ & \\
\hline Single & 10 & 15 & 25 \\
\hline Married & 0 & 5 & 5 \\
\hline Total & 10 & 20 & 30 \\
\hline $\mathrm{df}=1$ & $\chi^{2}$ crit. $=3.841$ & $\mathrm{P} \leq 0.05 \quad \chi^{2}$ obs. $=3.000$ \\
\hline
\end{tabular}

Table (8) shows that there is no significant difference between total items rate of patients' knowledge related to lumbar disk prolapse with marital status.

Table 9.Association between the Study Group's Educational Leveland Their Knowledge Total Items Rate in the

\begin{tabular}{|c|c|c|c|}
\hline \multirow{3}{*}{ Educational Level } & $\begin{array}{c}\text { Total Items Rate of Patients' Knowledge for } \\
\text { the Study Group Posttest }\end{array}$ & \multirow{3}{*}{ Total } \\
& $\begin{array}{c}\text { Moderate } \\
\text { f }\end{array}$ & $\begin{array}{c}\text { High } \\
\text { f }\end{array}$ & \\
\cline { 2 - 3 } & 2 & 0 & 2 \\
\hline Unable to Read and Write & 0 & 2 & 2 \\
\hline Read \& Write & 8 & 2 & 10 \\
\hline Primary School Graduate & 0 & 6 & 6 \\
\hline Intermediate School Graduate & 0 & 5 & 5 \\
\hline Secondary School Graduate & 0 & 1 & 1 \\
\hline Institute & 0 & 4 & 4 \\
\hline College and Above & 10 & 20 & 30 \\
\hline Total & 0 & & \\
\hline \multicolumn{2}{c}{$\mathrm{df}=6 \chi^{2}$ crit. $=12.592 \mathrm{P} \leq 0.05 \chi^{2}$ obs. $=22.800$} \\
\hline
\end{tabular}

Table (9) shows that there is a significant difference between total items rate of patients' knowledge related to lumbar disk prolapse with educational level.

Table 10.Association between the Study Group's Occupation and Their Knowledge Total Items Rate in the Posttest

\begin{tabular}{|c|c|c|c|}
\hline \multirow[b]{2}{*}{ Occupation } & \multicolumn{2}{|c|}{ Total Items Rate of Patients' Knowledge for the Study Group Post-Test } & \multirow[b]{2}{*}{ Total } \\
\hline & $\begin{array}{c}\text { Moderate } \\
\text { f }\end{array}$ & $\begin{array}{c}\text { High } \\
\text { f }\end{array}$ & \\
\hline Governmental Employee & 1 & 5 & 6 \\
\hline Free Job & 2 & 7 & 9 \\
\hline Retired & 0 & 1 & 1 \\
\hline Student & 0 & 1 & 1 \\
\hline Housewife & 7 & 6 & 13 \\
\hline Total & 10 & 20 & 30 \\
\hline $\mathrm{df}$ & $\chi^{2}$ crit. $=9.488$ & $\chi^{2}$ obs. $=4.712$ & \\
\hline
\end{tabular}


Table (10) shows thatthere is no significant difference between total items rate of patients' knowledge related to lumbar disk prolapse with occupation.

Table 11.Association between the Study Group's Residential Area and Their Knowledge Total Items Rate in the Posttest

\begin{tabular}{|c|c|c|c|}
\hline \multirow{2}{*}{ Residential Area } & \multicolumn{2}{|c|}{$\begin{array}{c}\text { Total Items Rate of Patients' Knowledge for the } \\
\text { Study Group Posttest }\end{array}$} & \multirow{2}{*}{ Total } \\
\hline & $\begin{array}{c}\text { Moderate } \\
\text { f }\end{array}$ & $\begin{array}{l}\text { High } \\
\text { f }\end{array}$ & \\
\hline Urban & 8 & 19 & 27 \\
\hline Rural & 2 & 1 & 3 \\
\hline Total & 10 & 20 & 30 \\
\hline \multicolumn{2}{|c|}{$\chi^{2}$ crit. $=3.841$} & ${ }^{2}$ obs. $=1.667$ & \\
\hline
\end{tabular}

Table (11) shows that there is no significant difference between total items rate of patients' knowledge related to lumbar disk prolapse with the residential area.

\section{Discussion}

\section{Discussion of the Socio-demographic Characteristics of Studied Sample (Table 1):}

The data analysis of (Table 1) reveal thatthe age groups were frequently from (30-39) years and (50 years and above) had affected equally for the patients of study group who have affected by lumbar disk prolapse, and for the control group the age of (30-39) years was most affected. This means that the age groups most usually affected are young people and old people. This result is similar to that of Ohtorithe ages score in patients with lumbar disk prolapse are $<40$ years old and also in patients who are more than 65 years old ${ }^{[11]}$. For supporting the finding of this study; Singh recorded that the patients with LDPwere from younger group aged 20 to $35 y$ years and the older group were aged $65 y$ years and above $\mathrm{e}^{[12]}$.

The present study reveals that the majority of patients $(56.7 \%)$ were female for the study group and (50\%) for each male and female was affected equally for the control group. The result of this study agrees with Miranda who stated that the males are less prone to LDP than females (male: female $46(43 \%): 61(57 \%))^{[13]}$. While the study of Wang disagrees with this study result, he stated that men begin have LDP more than women ${ }^{[14]}$. The majority of $(33.3 \%)$ were primary school graduation for the study group and $(26 \%)$ for the control group was primary school graduation also, this means that patients with LDP have an acceptable educational level to participate in the instructional program to improve their knowledge about lumbar disk prolapse.

Concerning the marital status, this study reveals that the majority of patients $(83.3 \%)$ were married for the study group and $(86.7 \%)$ of control group patients were married, too. This result in contrast with Nickel's study who found that marital status has no effect on patients with LDP ${ }^{[15]}$

The study reveals that the majority of patients $(43.3 \%)$ were housewives of the study group, and (33.3\%) equally for each the housewife and governmental employee were from the control group, to support this study, Hoy found out that the governmental businesses have an impact for patients with LDP. KailaKangasmentioned that job which isrequired bending and carrying frequently lead to injury to the back with highly rate ${ }^{[16,17]}$.

Regarding the monthly income of the study sample it appears that (46.7\%) of patients have barely sufficient monthly income of the study group, and the majority of (40\%) for the control group were sufficient monthly income. This result is in agreement with Nachemson who stated that people with low economics experience greater exposure to $\operatorname{LDP}^{[18]}$.

The findings of this study show that the majority of $(66.7 \%)$ living at private property these for study group while for the study group; $(63.3 \%)$ also living at a private property, this means that the patients in spite of living at private property and some had a sufficient monthly income, they had LDP.

The result shows that $(90 \%)$ of the study group living in urban areas, and $(86.7 \%)$ of the control group living in urban areas, too. To support this study, Williams reported that the disease rated as more than seventy percent in industrial nations than in rural ${ }^{[19]}$.

Discussion of the Clinical Characteristics of the Study Sample (Table 2):

The data analysis of (Table 2) that contains the distribution of clinical characteristicsvariables for both the study and control groups shows that most of the study group (76.7\%) didn't suffer from chronic disease, and $(83.3 \%)$ of the control group didn't suffer from chronic disease, too. The study of Jeffrey disagrees with this result when mentioned that the patients with LDPhavingother chronic diseases in addition to this disease ${ }^{[20]}$.

The majority of (93.3\%) of the study group weren't smoking, and (93.3\%) of the control group weren't smoking, too. This disagrees with Kandelwho reported that of 100 patients, $40 \%$ of those who smoked 
developed a LDP, also disagrees withGregory who reported that the smoky people are more prone to get LDP than nonsmoking people $\mathrm{e}^{[21,22]}$.

The finding of this study displays that a (70\%) hadn't family members with this disease, this for the study group while for control group; $(83.3 \%)$ hadn't it yet. To support this study result, Hestbaeksuggested that there is a role of genetic influences on liability to LDP.Also, Beckstein disagrees with this study when concluded that the genetic factors of this disease appears to have a dominant role ${ }^{[23,24]}$.

This study results show that $(93.3 \%)$ of the study group having no disk surgery previously, and (100\%) of the control group haven't it yet, too. This result is in contrast with Nickel who reported that more than a half of his study sample having a previous disk surgery ${ }^{[15]}$.

Concerning the previous admission to the hospital, the finding of this study reveals that the majority $(60 \%)$ of the study group haven't hospital admission and $(66.7 \%)$ for the control group haven't hospital admission, too.This study disagrees withEnthoven who reported that the patients with LDP are having more pain episodes that lead to hospital admission and try to find an extra health care ${ }^{[25]}$.

For the variable of having symptoms of LDP lead to work absenteeism, the result of this study indicates that a $(50 \%)$ of the study group don't have a governmental work, so they didn't have work absenteeism and $(53.3 \%)$ of the control group having work absenteeism. To support this study, Walker stated that the work absences of a (33\%) are common in the governmental employee patients. Also,Hestbaek agrees with this study when described that around a third of LDP workers are likely to have relapses of work absence ${ }^{\text {[26-27] }}$.

\section{Discussion of Mean of Scorefor the Study and Control Groups According to the Patients' level of Knowledge Related to LDP in the Pre-Test Period (Table 3):}

The finding of table (3) displays that a $(66.6 \%)$ of the study group patients have low knowledge level about the LDPwith low mean of score, and a (70\%) of the control group have a low knowledge level with low mean of score too,before the implementation of the instructional program. These results are in constant with the study of Stephen who reported that the patients' information was poor ${ }^{[28]}$. While Baisdendisagree with this once when he mentioned that the patients have pleasant responses about LDP disease due to watching and following a videos and instructions from the net ${ }^{[29]}$.

\section{Discussion of Mean of Scorefor the Study and Control Groups According to the Patients' level of Knowledge Related to LDP in the Post-Test Period (Table 4):}

The finding of table (4) reveals that a $(66.7 \%)$ of the study group patients have a high knowledge level and high mean of score after the completion of the instructional program, but a $(70 \%)$ of the control group patients have no enhancement in their knowledge level and also have a low mean of score in the posttest period.the study ofHanley agreed with this study results and stated that the group which received a teaching sessions getting more enhancement in their knowledge than the other group who not involved in the sessions

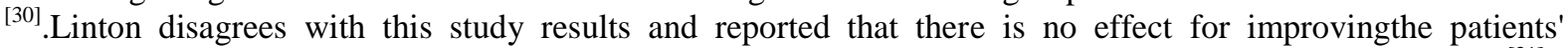
knowledge related to LDP disease after an implementation of a health program sessions for the study sample ${ }^{[31]}$.

\section{Discussion of theDistribution ofthe Rate of Scores According to the Study Group Posttest Knowledge Response about LDP (Table 5):}

The data analysis of table (5) which contains the distributionof the rate of scores for the study group in the posttest appears a high rate of score in $(63.3 \%)$ for anatomy part, $(60 \%)$ for etiology part, high rate of score in $(60 \%)$ for signs, symptoms and complications part, $(93.3 \%)$ for prevention methods part and $(66.7 \%)$ for total items rate of patient' knowledge. It can be consideredfromthis study finding that the knowledge of patients related to LDP has been improved after the implementation of the program.

\section{Discussion of Association between the Study Group Post-TestPatients' Knowledge Related to LDP and Their Demographic Data (Table 6 - 11):}

Age: the data analysis of table (6) shows that there is no significant difference between patients' knowledge related to LDP with their age at $(\mathrm{P} \leq 0.05)$, when analyzed by Chi-square test. This result disagrees with Jeffrey who revealed that the age correlates with the patients' information enhancement after the end of the sessions at $\mathrm{P}$ value $<0.001^{[20]}$

Gender: table (7) indicates that there is no significant difference between patients' knowledge related to LDP with gender at $(\mathrm{P} \leq 0.05)$. This result is in agreement with Nickel, U., et al., (2002) who found out that there is no significant difference regarding gender with participants' knowledge after the completion of teaching sessions $^{[15]}$. 
Marital Status: The finding of table (8) reveals that there is no significant difference between patients' knowledge related to LDP with marital status at $(\mathrm{P} \leq 0.05)$. This result is in contrast with the study of Jeffrey who stated that the most of the study sample marital status correlates with the patients' knowledge at $\mathrm{P}$ value $(<$ $0.001)^{[20]}$.

Educational Level: table (9) shows that there is a significant difference between patients' knowledge related to LDP with their educational levelat $(\mathrm{P} \leq 0.05)$. This study result is in correspond with the study done by Jeffrey who mentioned that there are significant differences in regard to patients' knowledge with educational level at $\mathrm{P}$ value $(0.04)^{[20]}$.

Occupation: The results of data analysis as presented in table (10) indicate there is no significant difference between patients' knowledge related to LDP with occupationat $(\mathrm{P} \leq 0.05)$. This resultsupported by Nickel study who reported that there is no significant difference regarding occupation with participants' knowledge after the completion of teaching sessions ${ }^{[15]}$.

Residential Area: the data analysis of table (11) shows that there is no significant difference between patients' knowledge related to LDP with their residential area at $(\mathrm{P} \leq 0.05)$. The researchers stated that the residential area didn't improve the relevant knowledge of patients about LDP.

\section{Conclusion}

The results show that the study group of LDP patients benefited from the implementation of the instructional program, and their knowledge was effectively enhanced and established.

\section{Recommendations}

The study recommends the importance of increasing awareness among patients about the LDP distributed through handbooks, explanatory posters, and performing an educational health programs through modern technological means (audio-visual) to follow a healthy back and spine safety during daily life activities at home and at work. Finally, the researcher suggests performing new studies to include more patients for as long as possible to follow how their quality of life.

\section{References}

[1]. Xian Chang, Bin Chen, Hai-yin Li, et al., The safety and efficacy of minimally invasive discectomy: a meta-analysis of prospective randomized controlled trials. Review Article. International Orthopedics (SICOT), (2014); 38: 1225-1234.

[2]. Hoy D., Smith E., Cross M., et al. (2014). The global burden of musculoskeletal conditions for 2010: an overview of methods. Ann Rheum Dis.doi: 10.1136/annrheumdis- 2013-204344.

[3]. Macfarlane G., Jones E., Prescott G., et al; MUSICIAN Study Team. The prevalence and management of low back pain across adulthood: results from a population-based cross-sectional study (the MUSICIAN study). Pain. 2012 Jan; 153(1):27-32.

[4]. Modic T., Nancy A., Jeffery S., et al., Acute Low Back Pain and Radiculopathy: MR Imaging Findings and Their Prognostic Role and Effect on Outcome. Radiology. 2005:237, 597-604.

[5]. Shobeiri E., Khalatbari M., Taheri M., et al., Magnetic resonance imaging characteristics of patients with low back pain and those with sciatica. Singapore medical journal. 2009 Jan; 50(1):87-93.

[6]. Siddiqui A., Rafique M., Ahmad M., et al., Role of magnetic resonance imaging in lumbar spondylosis. J Coll Physicians Surg Pak. 2005 Jul; 15(7):396-9.

[7]. Schoen D.: Adult Orthopedic Nursing( $1^{\text {st }}$ edition, Lippincott Williams \&Wilkins, Philadelphia, NewYork, 2000. p. 250).

[8]. Ebnezar J.: Orthopedic for Nurses ( ${ }^{\text {st }}$ edition, JAYPEE BROTHERS MEDICAL BUPLISHERS, New Delhi, 2005, p.: 347- 351).

[9]. Daniel C., Karen J., Richard A., and Paul, G.:A Review of the Evidence for the Effectiveness, Safety, and Cost of Acupuncture, Massage Therapy, and Spinal Manipulation for Back Pain. Ann Intern Med. 2003; 138(11):898-906.

[10]. Campbell P., Wynne-Jones G., Muller S., et al. (2013). The influence of employment social support for risk and prognosis in nonspecific back pain: a systematic review and critical synthesis. Int Arch Occup Environ Health.86:119-137. Doi: 10.1007/s00420-012-0804-2.

[11]. Ohtori S., Ito T., Yamashita M., et al.,Group. Evaluation of low back pain using the Japanese Orthopedic Association Back Pain Evaluation Questionnaire for lumbar spinal disease in a multicenter study: differences in scores based on age, sex, and type of disease.J Orthop Sci. 2010 Jan; 15(1):86-91.

[12]. Singh et al.: BMC Musculoskeletal Disorders. Bio Med Central 2013, 14:215. Available at: http://www.biomedcentral.com/1471$2474 / 14 / 215$.

[13]. Miranda L., Johannes D., John O’Dowd, et al., Daily functioning and self-management in patients with chronic low back pain after an intensive cognitive behavioral programme for pain management. Eur Spine J (2010) 19:1517-1526.

[14]. Wang Y., Battie M., Boyd S., et al. (2011).The osseous endplates in lumbar vertebrae: thickness, bone mineral density and their associations with age and disk degeneration. Bone:48, 804-809.

[15]. Nickel U., Egle J., Rompe P., et al., Somatisation predicts the outcome of treatment in patients with low back pain. The Journal of Bone and Joint Surgery. Vol. 84-B, No. 2, March 2002

[16]. Hoy D., Brooks P., et al., The Epidemiology of low back pain. Best 2010 Dec; 24 (6):769-81.

[17]. Kaila-Kangas L., Leino-Arjas P., Karppinen J., et al. (2009). History of physical work exposures and clinically diagnosed sciatica among working and nonworking Finns aged 30 to 64. Spine34, 964-969. 
[18]. Nachemson A., Waddell G., Norlund A. 2000. Epidemiology of neck and low back pain. In Neck and back pain: The scientific evidence of causes, diagnosis and treatment (Ed. Nachemson AL, Jonsson E): 165-188, Lippincott Williams \& Wilkins, Philadelphia.

[19]. Williams F., Manek N., Sambrook P., et al. (2007) Schmorl's nodes: common, highly heritable, and related to lumbar disc disease. Arthritis Rheum57, 855-860.

[20]. Jeffrey A., Alan S., Wenyan Z., et al., Effectiveness of Surgery for Lumbar Stenosis and Degenerative Spondylolisthesis in the Octogenarian Population. Analysis of the Spine Patient Outcomes Research Trial (SPORT) Data. Bone Joint Surg Am. 2015; 97: 177-85.

[21]. Kandel R., Roberts S., Urban J. (2008) Tissue engineering and the intervertebral disc: the challenges. Eur Spine J17(Suppl 4),480491.

[22]. Gregory D., Callaghan J. (2011). A comparison of uniaxial and biaxial mechanical properties of the annulus fibrosus: a porcine model. J BiomechEng133, 024503

[23]. Hestbaek, L., Iachine, I., Leboeuf-Yde, C., et al. 2004. Heredity of low back pain in a young population: A classical twin study. Twin Research 7: 16-26.

[24]. Beckstein J., Sen S., Schaer T., et al. (2008). Comparison of animal discs used in disc research to human lumbar disc: axial compression mechanics and glycosaminoglycan content. Spine (Phila Pa 1976)33, E166-E173.

[25]. Enthoven P., Skargren E., Oberg B., Clinical course in patients seeking primary care for back or neck pain: a prospective 5-year follow-up of outcome and health care consumption with subgroup analysis. Spine. 2004; 29(21):2458-65.

[26]. Walker B., Muller R., Grant W. Low back pain in Australian adults: the economic burden. Asia Pac J Public Health. 2003; 15(2):79-87.

[27]. Hestbaek L., Leboeuf-Yde C., Manniche C. 2003b. Low back pain: what is the long-term course? A review of studies of general patient populations. European Spine Journal 12: 149-165.

[28]. Stephen K., Jeffrey G.: Degenerative Disk Disease. Medscape. 2014. Available at:http://emedicine.medscape.com/article

[29]. Baisden J., Carragee E., Resnick D., et al.: Literature Review. Surgery for Low Back Pain: A Review of the Evidence for an American Pain Society Clinical Practice Guideline. Spine. (2009); 34 (10):1094-1109.

[30]. Hanley E., Herkowitz H., Kirkpatrick J., et al. (2010). Debating the value of spine surgery. J Bone Joint Surg Am92, 1293-1304

[31]. Linton S., van Tulder M. 2001. Preventive interventions for back and neck pain problems: What is the evidence? Spine26: 778-787. 